\title{
Improved Maternal and Perinatal Mortalities by TrainedMedical Assistant Staffs in Rural Tanzania
}

\author{
Kihaile PE*, Mbaruku G, and Pemba S
}

Ifakara Health Institute, PO Box 37, Ifakara, Tanzania

\begin{abstract}
Objectives: In Sub Sahara Africa, it is estimated that about $10 \%$ of pregnant mothers will develop complications that must be attended by medical staff with skills on Comprehensive Emergency Medical Operative Care (CEMOC), but their heavy shortage, specifically in rural areas, is a major cause of the high maternal and perinatal mortality in the region. Improvement of the situation was the aim of this study.

Methods: In view of this, we trained 36 Non physician Clinicians (NPCs) from 18 disadvantaged Rural Health Facilities. From each of the 18 facilities, we selected one Assistant Medical Officer (AMOs) and one Nurse. The AMOs underwent a 12 weeks training on $\mathrm{CEMOC}$ including surgical skills while the Nurses underwent also a 12 weeks training on Anesthesia and Resuscitation of the new born.

Results: By the end of the training, the AMOs did $483 \mathrm{C} / \mathrm{S}$ under supervision and no maternal death occurred while the Nurses administered anesthesia and no maternal death occurred. We are now following up the NPCs in their rural health facilities to see their impact on maternal and perinatal mortality.
\end{abstract}

Keywords: Maternal mortality; Tanzania; Trained assistant medical officer; C-section; Abnormal labor; Nurse midwife; Anesthesia

\section{Introduction}

About 800 women died of pregnancy or child birth related complications daily mainly in developing countries and most of these deaths are preventable [1]. Tanzania is no exception as the Maternal Mortality Ratio stands high at 460/100,000 live Births versus 3 and $4 / 100,000$ for Singapore and Sweden, respectively. While the Perinatal Mortality ratio is also high (20-39/1,000) compared with 6 and 7/1,000 for German and Japan, respectively [2-4].

WHO estimates that about 1 in 10 pregnant women in Tanzania need emergency maternal health care provided by a skilled medical staff in order to survive in contrast to about 1 in 15 worldwide and the above problems in Tanzania are compounded by the findings of very high physician to patient ratio which is close to $1: 25,000$ as well as the fact that only $20 \%$ of these physicians practice in rural areas where the vast majority of population $(>80 \%)$ lives $[2,3]$.

In Year 2000, the international community adopted the Fifth Millennium Development Goal (MDG5) in which the community committed itself to reducing the Maternal and Perinatal Mortality by $75 \%$ between by 2015 . Unfortunately until now only $10 \%$ reduction has been achieved $[2,3]$.

Therefore, because of the acute shortage of physicians in especially rural areas, there is an urgent need to train Non Physcian Clinician (NPCs), who were Assistant Medical Officers who were medically educated, they are allowed by Law in Tanzania and in many African countries to do $\mathrm{C} / \mathrm{S}$ and other surgical operations.

\section{Objective}

Our objective was to train 1) NPCs namely Assistant Medical Officers (AMOs) on surgical skills and 2) Nurse midwives on anesthesia, so that as team members, they can provide CEMOC at remote, disadvantaged rural areas.

\section{Methods}

The NPCs were selected mainly from remote disadvantaged
Upgraded Health Centers (HCs) in the rural areas of Tanzania. These rural areas had poor transport infrastructure making them almost inaccessible during the long rains.

Two NPCs namely one Assistant Medical Officer (AMO) and one Nurse Midwife were chosen from the each of the HCs. The AMO training included CEMOC and hands-on-training on surgical skills. The surgical procedures they did under supervision included Cesarean Section (C/S), Ruptured uterus, Laparotomy for Ectopic Pregnancy, and abortions and others.

The nurse midwives were trained on administering Spinal and General anesthesia as well as resuscitating babies born with low Apgar score. The duration of training was 12 weeks at ST. Francis Referal Hospital, Ifakara.

During the first 12 weeks from Monday to Friday. The time table was as follows;

1) $7.45 \mathrm{am}-9.00 \mathrm{am}$ they presented the emergency cases they had managed under supervision during the previous night.

2) 9.00 am-1.00 pm major ward round in the Maternity wards.

3) 3.00-5.00 pm; Lecture on EMOC topics.

When cases with indications for surgical procedure were found during the ward rounds, the AMOs did the procedures under supervision in the theater.

4) Also a Duty Roster for night duty for the AMOs was made and they attended the patients at night under supervision.

*Corresponding author: Paul E Kihaile, Ifakara Health Institute, PO Box 37, Ifakara, Tanzania, E-mail: pkihaile@ihi.or.tz

Received April 01, 2013; Accepted April 30, 2013; Published May 10, 2013

Citation: Kihaile PE, Mbaruku G, Pemba S (2013) Improved Maternal and Perinatal Mortalities by Trained Medical Assistant Staffs in Rural Tanzania. J Health Med Informat S11: 007. doi:10.4172/2157-7420.S11-007

Copyright: ( 2013 Kihaile PE, et al. This is an open-access article distributed under the terms of the Creative Commons Attribution License, which permits unrestricted use, distribution, and reproduction in any medium, provided the original author and source are credited. 
Citation: Kihaile PE, Mbaruku G, Pemba S (2013) Improved Maternal and Perinatal Mortalities by Trained Medical Assistant Staffs in Rural Tanzania J Health Med Informat S11: 007. doi:10.4172/2157-7420.S11-007

Page 2 of 3

5) Regarding the Nurse Midwives, for 12 weeks under supervision proceeded to administer anesthesia to all patients, be they Obstetrical or general Surgery cases, undergoing surgery from 8.00 am until 3.00 $\mathrm{pm}$. Then had lectures from $3.00 \mathrm{pm}$ to $5 \mathrm{pm}$ and after which they did night duties according to Duty Roster.

They were also taught neonatal resuscitation after C/S in low Apgar score babies.

\section{Results}

A total of 36 NPCs from disadvantaged remote Health Facilities were recruited for training and were in two groups (Table 1). The first group of NPCs consisted of 18 AMOs who underwent training on CEMOC which included Obstetrical surgical skills and the second group of NPC consisted of 18 Nurse Midwives who underwent training on Anesthesia.

There were 1,912 deliveries out which $70 \%$ were spontaneous vertex deliveries, $25 \% \mathrm{C} / \mathrm{S}, 3 \%$ breech and only $2 \%$ were vacuum extraction. There were 4 cases of destructive operation due to intrauterine fetal death (Table 2).

\section{Obstetrics hemorrhage}

The ruptured uterus cases underwent laparotomies and fresh still births were delivered in 27 cases (Table 3).

The majority postpartum hemorrhage ( $\mathrm{PPH}$ ) cases were mild and due to uterine atony and only 4 required bimanual uterus compression.

There were 5 cases of cervical tear which were sutured in the theatre as well as 6 cases of retained placenta underwent manual removal in the theater.

No maternal death occurred.

\begin{tabular}{|l|l|}
\hline NPC & Number \\
\hline Assistant Medical Officers & 18 \\
\hline Nurse midwives & 18 \\
\hline Total No. NPCs & 36 \\
\hline
\end{tabular}

Table 1: Number of NPCs trained for 12 weeks.

\begin{tabular}{|l|l|l|l|}
\hline Procedure & Number & $\begin{array}{l}\text { \% Total } \\
\text { Deliveries }\end{array}$ & $\begin{array}{l}\text { Average No.of cases } \\
\text { attended by Each NPC }\end{array}$ \\
\hline SVD & 1339 & $70 \%$ & 74 \\
\hline C/S & 483 & $25 \%$ & 27 \\
\hline Breech & 52 & $3 \%$ & 2 \\
\hline Vacuum & 38 & $2 \%$ & 2 \\
\hline $\begin{array}{l}\text { Total No. of Live } \\
\text { Deliveries }\end{array}$ & 1912 & & \\
\hline Destructive Operations & 4 & & \\
\hline
\end{tabular}

SVD=Spontaneous Vertex Delivery

$\mathrm{AMO}=$ Assistant Medical Officer

Table 2: Mode of Deliveries attended by AMO.

\begin{tabular}{|l|l|l|}
\hline Procedure & Number & Average in each AMO \\
\hline $\begin{array}{l}\text { Post Partum Hemorrhage/Retained } \\
\text { Placenta }\end{array}$ & 35 & 2 \\
\hline Ruptured Uterus & 27 & 1.5 \\
\hline Antepartum Hemorrhage & 22 & 1 \\
\hline Maternal Death & 0 & \\
\hline
\end{tabular}

$\mathrm{AMO}=$ Assistant Medical Officer

Table 3: Obstetric-Haemorrhage-Cases attended by AMO.

\begin{tabular}{|l|l|}
\hline Indication for C/S & Number \\
\hline Repeat C/S & 106 \\
\hline Obstructed labour & 98 \\
\hline Prolonged labour & 89 \\
\hline Fetal Distress & 61 \\
\hline Severe pre eclampsia+eclampsia & 54 \\
\hline Breech+other malpresentations & 31 \\
\hline Antepartum hemorrhage & 22 \\
\hline Failed induction & 14 \\
\hline Cord prolapse & 12 \\
\hline Others & 9 \\
\hline Maternal death post C/S & 0 \\
\hline Fistula post C/S & 0 \\
\hline Total & 483 \\
\hline
\end{tabular}

Table 4: Cesarean Sections.

\begin{tabular}{|l|l|l|}
\hline $\begin{array}{l}\text { Anesthetic } \\
\text { Procedure }\end{array}$ & $\begin{array}{l}\text { Number of cases } \\
\text { administered }(\% \text { to Total) }\end{array}$ & $\begin{array}{l}\text { Average cases done by } \\
\text { a nurse midwife }\end{array}$ \\
\hline Spinal anesthesia & $348(45 \%)$ & 19 \\
\hline $\begin{array}{l}\text { General anesthesia by } \\
\text { Intubation }\end{array}$ & $142(18 \%)$ & 8 \\
\hline Bolus Ketamine & $289(37 \%)$ & 16 \\
\hline Total & $779(100 \%)$ & \\
\hline
\end{tabular}

Table 5: Number of Anesthetic Procedures done by 18 Nurse Midwives.

\section{Cesarean Section}

1) The Commonest indication for $C / S$ was repeat $C / S(22 \%)$ the majority of which were due to two or three previous C/S (Table 4).

2) Obstructed labour (20\%) and prolonged labour (18\%) came second and third, respectively.

3) Only $2 \%$ of the $\mathrm{C} / \mathrm{S}$ was due to failed induction.

4) 19 patients (4\%) had post-operative wound sepsis.

5) No case of maternal death or fistula post C/S occurred.

\section{Anesthesia for patients undergoing $\mathrm{C} / \mathrm{S}$ and general surgery}

Spinal anesthesia was preferred most (45\%) followed by bolus ketamine (37\%) and general anesthesia with intubation was least (18\%).

No case of maternal death due to anesthesia was experienced during the period of training (Table 5).

\section{Discussion}

The AMOs had good exposure to doing C/S as each of them did an average of $27 \mathrm{C} / \mathrm{S}$ under supervision. The C/S rate was $25 \%$ and comparable with rates which range from $15 \%$ worldwide to $40 \%$ in China and Italy $[5,6]$.

During teaching sessions, it was emphasized to AMOs that identifying the correct indication for $\mathrm{C} / \mathrm{S}$ was crucial and not the procedure itself per se and furthermore, for patients in labour, Partograms were vital in making a decision on whether to proceed to do a $\mathrm{C} / \mathrm{S}$ or vaginal delivery.

Before starting the training, the AMOs could not fill the Partogram properly as indicated by a Pre-test given, but under supervision they all learnt to fill partograms correctly and consequently detected any abnormality early in labour and intervened before fetal or maternal compromise occurred. 
The use of prophylactic antibiotic, early ambulation (12-24 hours) after $\mathrm{C} / \mathrm{S}$ for even patients who were given spinal anesthesia, and continuous catheter drainage for 7 for obstructed labour patients were emphasized. Consequently the morbidity was low i.e. sepsis rate $4 \%$ as well as no fistula, and there was no maternal death.

The NPCs in their rural facilities did not know the use of vacuum extraction machine during assisted vaginal delivery. Therefore, they had to refer to distant district hospitals patients with eclampsia even when they were in second stage with descent of head at station +2 , whom otherwise would have easily undergone assisted vaginal delivery by vacuum extraction.

Correct indications and techniques of vacuum extraction during assisted vaginal delivery were reiterated in order to reduce unnecessary $\mathrm{C} / \mathrm{S}$.

The low rate of $2 \%$ compares with a rate of $1 \%$ obtained in a Nigeria [6] but differs with higher rates of $15 \%$ or more in Europe [7].

The low rates of vacuum extraction use in developing countries are associated with the false belief that the procedure is associated with increasing HIV transmission infection rates although there is no documented study on this.

Only 4 patients presented with the right indication for destructive operation. They were all referrals from rural peripheral facilities and they all had obstructed labour with intrauterine fetal death in the second stage of labour with the head at station +2 . Usually such patients with intrauterine fetal death undergo $\mathrm{C} / \mathrm{S}$ at district hospital but the NPCs were shown how to do destructive operation.

Destructive operation are not popular in developing countries and Ahaji et al. [6], found a rate of $0.5 \%$ of all assisted vaginal deliveries despite the fact that a lot of patients presenting with obstructed labour from peripheral rural health facilities have dead fetus and if $\mathrm{C} / \mathrm{S}$ are done in such patients they are usually associated with severe sepsis which could be fatal $[5,6]$.

The NPCs were also trained to prevent and manage obstetric hemorrhage which is the number one cause of maternal mortality in developing countries [1] and it was reiterated to them that active management of third stage of labour was crucial.

Before starting the course, they did not know that prophylactic Misoprostol (PGE1) given per rectal in the third stage of labour could prevent $\mathrm{PPH}$. At risk women at the prenatal clinic who were likely to deliver at home were taught by NPC to use per rectal misoprostol after child birth for prevention of $\mathrm{PPH}$.

The importance of Misoprostol in patients with low Bishop Score undergoing induction of labour and also during induction for intrauterine fetal death was realized as shown by the low failure rate (14\%) of inductions of labour.

The pre-test on the management of pre-eclampsia and eclampsia revealed that the NPCs were not aware of the use of $\mathrm{MgSO}_{4}$ and instead they stocked Diazepam for eclampsia only and no anticonvulsants was given to cases of severe pre eclampsia.

During the course they learnt the correct use of $\mathrm{MgSO}_{4}$ as exemplified by the low morbidity i.e. no case of stroke or mortality among the severe preeclampsia and eclamptic patients.

The Nurses who underwent training in anesthesia had had no previous exposure to anesthesia and they used to practice only midwifery and other nursing duties at their health facilities.

By the end of the course, they all mastered spinal anesthesia which was commonly used in $\mathrm{C} / \mathrm{S}$. The cases requiring general anesthesia with intubation were few (average 8 cases) because of the erratic electricity supply hence risky to intubate and instead administered bolus ketamine as exemplified by an average of 16 patients attended by each nurse.

There was neither mortality nor serious morbidity among cases they attended.

\section{Conclusion}

In conclusion, because of the severe shortage of doctors in developed countries and especially in rural areas, this project has shown that training NPCs to do CEMOC is quite feasible and this cadre can work in remote disadvantages health facilities with a view to reducing the maternal and perinatal mortality. Follow up of the NPCs in their facilities to see their impact on maternal and perinatal mortality rates is underway.

\section{References}

1. WHO (2011) Maternal Mortality Fact Sheet.

2. WHO (2012) WHO Trends in maternal mortality: 1990 to 2010. UNICEF UNFPA and world bank estimates.

3. WHO (2004) Neonatal and perinatal mortality: country, regional and global estimates.

4. Godfrey M, Roosmalen JV, Iluminata K, Filigona B, Bergström S (2009) Averting maternal death and disability Perinatal audit using the 3-delays mode in western Tanzania. Internat J Gynecol Obstet 106: 85-88.

5. Betrán AP, Merialdi M, Lauer JA, Bing-Shun W, Thomas J, et al. (2007) Rates of caesarean section: analysis of global, regional and national estimates. Paediatr Perinat Epidemiol 21: 98-113.

6. Ahaji SE, Shittu So, Sule ST (2009) Annals of African Medicine Society. 8: 9599.

7. Hillier CE, Johanson RB (1994) Worldwide survey of assisted vaginal delivery Int J Gynaecol Obstet 47: 109-114. 